\title{
Hypogammaglobulinaemia in a patient with ring chromosome 21
}

Shouichi Ohga, Futoshi Nakao, Osamu Narazaki, Naoki Fusazaki, Tomonobu Aoki, Kenji Kamesaki, Toshiro Hara

\begin{abstract}
An 8 year old boy with ring chromosome 21 who was susceptible to sinorespiratory infections due to hypogammaglobulinaemia is reported. He presented with the characteristic features of monosomy 21 syndrome, such as psychomotor retardation, hypertonia, large saccular ears, prominent nasal bridge, micrognathia, thrombocytopenia, and patent ductus arteriosus. His serum IgG concentration was less than $1.5 \mathrm{~g} / 1$ at 3 years and 6 months of age after repeated hospitalisations with pneumonia, otitis media, and convulsions. Regular replacement of intravenous gammaglobulin effectively reduced such infectious episodes. A predisposition to infection in patients with ring chromosome 21 may be explained by hypogammaglobulinaemia and merit treatment with gammaglobulin.

(Arch Dis Child 1997;77:252-254)
\end{abstract}

Keywords: gammaglobulin treatment; hypogammaglobulinaemia; monosomy 21 syndrome; ring chromosome 21

Monosomy 21 syndrome ( $21 \mathrm{q}^{-}$or 21 -deletion syndrome) is a rare congenital anomaly characterised by such clinical features as intrauterine growth retardation (IUGR), psychomotor retardation, hypertonia, antimongoloid slant, prominent nasal bridge, large and saccular low set ears, and micrognathia. ${ }^{12}$ Despite there having been several reports dealing with this syndrome, increased susceptibility to infections and associated immunological defects have not been clearly described. ${ }^{3-6}$ The World Health Organisation classification of primary immunodeficiency disease ${ }^{7}$ lists trisomy 21 (Down's syndrome), deletions or rings of chromosome $18\left(18 \mathrm{p}^{-}\right.$or $\left.18 \mathrm{q}^{-}\right)$, and Turner's syndrome (XO), but not monosomy 21 as constitutional chromosomal defects associated with immunodeficiency.

We describe a case of ring chromosome 21, where there was the characteristic manifestation of monosomy 21 syndrome together with hypogammaglobulinaemia, and where the infection was successfully controlled with gammaglobulin treatment. The clinical significance of hypogammaglobulinaemia in monosomy 21 is discussed.

\section{Case report}

A Japanese boy aged 3 years 6 months was referred to our hospital for investigation into the cause of recurrent infections. His parents were cousins, and a 2 year old male sibling was healthy. There was no immunological disease or chromosomal abnormality among relatives. He had been born to a healthy mother with no history of medication or infection during the pregnancy at 42 weeks' gestation and weighed $2098 \mathrm{~g}$ at birth. IUGR was diagnosed antenatally. At 47 days, patent ductus arteriosus and mild aortic stenosis were found. Cytogenetic study of peripheral lymphocytes revealed a karyotype of 46,XY,r(21)(p11 q22) in all 20 cells examined. High resolution analysis showed the fusion site of a ring chromosome 21 (fig 1). Heart failure resolved after ligation of the patent ductus arteriosus at 12 months of age. Convulsions emerged at 19 months of age and he suffered from acute hepatitis of an unknown cause at 24 months of age. Thereafter, he was hospitalised seven times during a period of 18 months because of pneumonia, otitis media, and convulsions.

On admission, physical examination revealed an alert short, skinny boy of $89 \mathrm{~cm}$ in height ( $-6.1 \mathrm{SD})$ weighing $8629 \mathrm{~g}(-3.9 \mathrm{SD})$ with high fever $\left(39^{\circ} \mathrm{C}\right)$, tachycardia, and tachypnoea due to pneumonia. Antimongoloid slant, prominent and broad nasal bridge, large saccular low set ears, high arched palate, micrognathia, and cryptorchidism were noted, but there was no anaemia, jaundice, skin eruption, purpura, lymphadenopathy, or hepatosplenomegaly. Auscultation revealed

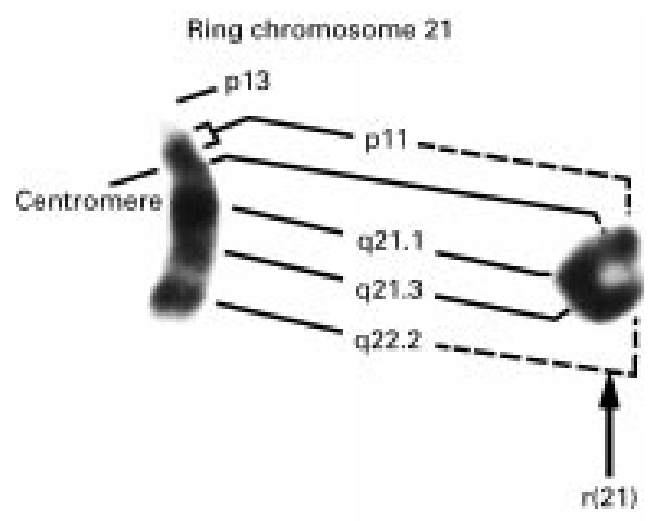

Figure $1 \quad G$ banding karyotype and high resolution analysis of peripheral blood obtained from the patient showed 46,XY,r(21) (p11 q22). 
respiratory moist rales and an ejection systolic heart murmur (Levine 3/6) at the left sternal border. Neurological examination demonstrated general hypertonicity, hyperactive reflexes, and psychomotor retardation. He was able to roll over, but could not crawl or sit up by himself. Peripheral blood counts showed a white cell count $15.4 \times 10^{9} / 1$ with $3 \%$ metamyelocytes, $12 \%$ bands and $38 \%$ segmented neutrophils, $26 \%$ lymphocytes, $20 \%$ monocytes, and $1 \%$ eosinophils, red cell count $4140 \times$ $10^{9} / 1$, haemoglobin $123 \mathrm{~g} / \mathrm{l}$, and a platelet count of $45 \times 10^{9} / 1$. Blood chemistry indicated normal liver and kidney function. Analysis of the serum protein fraction before the first administration of gammaglobulin showed a total protein level of $41 \mathrm{~g} / 1$ (normal range 67-83), with $63.7 \%$ albumin (59.7-70.8), $7.0 \%$ alpha $_{1}-(1.6-2.9), 17.3 \%$ alpha $-(5.8-$ $9.1), 9.5 \%$ beta- (7.1-10.8), and $2.5 \%$ gammaglobulin (11.6-20.9) (1.0 g/l). The low albumin concentration was found only at that time. There was no protein loss in urine and stool. Serum immunoglobulin concentrations and specific antibody responses to measles immunisation were not examined before the first administration of gammaglobulin (10 g). Serum immunoglobulin concentrations two months after the first gammaglobulin replacement were documented as IgG $3.9 \mathrm{~g} / 1$ (normal range 5.3-13.4), IgA $<0.2 \mathrm{~g} / 1(0.3-1.7), \operatorname{IgM}$ $0.3 \mathrm{~g} / 1(0.6-2.8)$, and $\operatorname{IgE}<24 \mu \mathrm{g} / 1(24-4320)$. Neutrophil function was normal with regard to superoxide anion release and chemoattractance. The expression of CD18 on lymphocytes and total haemolytic activity of complement were normal. Surface marker analysis of peripheral mononuclear cells revealed $70 \% \mathrm{~T}$ cells, $15 \% \mathrm{~B}$ cells, with a CD4/ CD8 ratio of 0.78 , and no skewing $\mathrm{B}$ cell subpopulation expressing any specific immunoglobulin class. Mitogen response of lymphocytes to phytohaemagglutinin and concanavalin A was normal. Superoxide dismutase activity (SOD) was normal (10.4\%; normal range $6.4-12.8 \%$ ). The findings of analyses of Bruton's tyrosine kinase (Btk) activity and the Btk gene were normal as assessed by a previous method. ${ }^{8}$ Bone marrow aspiration yielded normocellular marrow with no abnormal cells. Platelet associated antibody was not detected.

The patient was hospitalised 11 times before his referral at 3 years 6 months of age, the first three admissions were for cardiac management, and the remaining eight were for the treatment of infections. However, during the next four years while receiving gammaglobulin replacement (2.5-5 g/month), he was hospitalised only once for the control of seizures, while maintaining serum IgG concentrations in excess of $4.0 \mathrm{~g} / 1$.

\section{Discussion}

This is the first reported case of a patient with ring chromosome 21 demonstrating the clinical association of hypogammaglobulinaemia and recurrent infections. Monosomy 21 syndrome was originally defined as group G monosomy; the first description was of an infant with multiple anomalies whose karyotype was $45, \mathrm{XY},-\mathrm{G} / 46, \mathrm{XY}, \mathrm{r}(\mathrm{G})$, characterised as antimongolism in contrast to trisomy 21 (Down's syndrome). ${ }^{1}$ Advanced chromosome banding techniques have classified the group $G$ monosomy into 21-deletion and 22-deletion syndromes based on their distinct clinical features. The patient described here showed the common phenotypic pictures described as monosomy 21 syndrome, such as growth retardation, psychomotor retardation, large saccular ears, prominent nose, high arched palate, and hypertonicity, along with unfamiliar features including cardiac anomaly, cryptorchidism, and thrombocytopenia, but with no skeletal malformation or eosinophilia. Although several reports have been published on monosomy 21 syndrome, ${ }^{1-6}$ including ring chromosome $21,{ }^{9-12}$ hypogammaglobulinaemia was not described in detail. There was no report on the high resolution analysis of ring chromosome 21 associated with hypogammaglobulinaemia. In the review of Warren and Rimoin hypogammaglobulinaemia was reported in two out of three patients with $G$ deletion (21-deletion) syndrome, but they provided no information about deficient IgG concentrations, cellular immunological functions or the clinical severity of infections. ${ }^{1}$ The patient studied by Gripenberg et al showed decreased gammaglobulin concentrations, although no IgG levels were described. ${ }^{4}$ Kaneko et al reported a male infant with ring chromosome 21 who suffered from occasional dyspnoeic pneumonias with low serum IgG concentrations $(4.1 \mathrm{~g} / \mathrm{l}){ }^{6}$

Some subjects with ring chromosome 18 have an IgG deficient state and this can partly lead to recurrent infections. ${ }^{13-15}$ The ring chromosome formation follows terminal deletions and the amount deleted may result in the clinical variety of presentation. The patient described here showed normal SOD activity and normal CD18 expression. Patients with an interstitial deletion of the chromosome segment $21 \mathrm{q} 11$ to $21 \mathrm{q} 21.3$ have minor anomalies and mental retardation, but not hypogammaglobulinaemia. ${ }^{16}$ In this context, the high resolution analysis of ring chromosome 21 (fig 1) suggests that hypogammaglobulinaemia associated genes may be located on the terminal deleted sites distal from q22.2 (SOD1) or q22.3 (CD18). ${ }^{17}$ On the other hand, Theodoropoulos et al suggest that the critical region for a severe phenotype of $21 \mathrm{q}^{-}$ lies within 21q22.1-22.2. ${ }^{18}$ Most cases described as monosomy 21 represent unbalanced translocations or other structural aberrations resulting in only partial monosomy $21 .^{19}$ Further DNA studies are required to explore the possibility that the hypogammaglobulinaemia is due to $21 \mathrm{q}^{-}$deletion or other accompanied defects. ${ }^{20}$ The examination of Btk genes to exclude the chance association of $\mathrm{X}$ linked agammaglobulinaemia with this syndrome showed no abnormality. No excessive protein loss was evident. These indicate a congenital defect in immunoglobulin production in this syndrome, but do not confirm a specific intrinsic abnormality within the B cells. Our observation may provide helpful information in 
elucidating the basic mechanism of $\mathrm{B}$ cell maturation, as well as in the further mapping of chromosome 21 .

We are grateful to Shoji Hashimoto, MD and Satoshi Tsukada, MD (Third Department of Internal Medicine, Osaka University Medical School, Osaka) for the analyses of Btk kinase activity and the Btk gene. The English was revised by Miss K Miller (Royal English Language Centre, Fukuoka, Japan). This work was supported in part by a grant from the Ministry of Health and Welfare for Primary Immunodeficiency Diseases.

1 Warren RJ, Rimoin DL. The G deletion syndromes. 7 Pediatr 1970;77:658-63.

2 Fryns JP, D'Hondt F, Goddeeris P, van den Berghe H. Full monosomy 21: a clinically recognizable syndrome? Hum Genet 1977;37:155-9.

3 Wisniewski K, Dambska M, Jenkins C, Sklower S, Brown WT. Monosomy 21 syndrome: further delineation including clinical, neuropathological, cytogenetic and biochemiing clinical, neuropathological, cytogenet

4 Gripenberg U, Elfring J Gripenberg L. A 45,XX,21-child: attempt at a cytological and clinical interpretation of the attempt at a cytological and clinical

5 Halloran KH, Breg WR, Mahoney MJ. Monosomy in a retarded female infant. $\mathcal{F}$ Med Genet 1974;11:386-9.

6 Kaneko Y, Ikeuchi T, Sasaki M, Satake Y, Kuwajima S. A male infant with monosomy 21. Hum Genet 1975;29:1-7.

7 Primary immunodeficiency diseases; report of a WHO scientific group. Clin Exp Immunol 1995;99(suppl 1):1-24

8 Hashimoto S, Tsukada S. Matsuzaki M, et al. Identification of Bruton's tyrosine kinase (Btk) gene mutations and characterization of the derived proteins in $35 \mathrm{X}$-linked agammaglobulinemia families: a nationwide study of Btk deficiency in Japan. Blood 1996;88:561-73.

9 Zergollern L, Muzinic D, Raic Z. Ring chromosome 21. Acta Medica Iugoslavica 1989;43:147-56.
10 McGinniss MJ, Kazazian HH Jr, Stetten G, et al. Mechanisms of ring chromosome formation in 11 cases of human ring chromosome 21. Am f Hum Genet 1992;50:1528 .

11 Bartsch O, Petersen MB, Stuhlmann I, et al. 'Compensatory' uniparental disomy of chromosome 21 in two cases. $\mathcal{F}$ Med Genet 1994;31:534-40.

12 Falik-Borenstein TC, Pribyl TM, Pulst SM, et al. Stable ring chromosome 21: molecular and clinical definition of the lesion. Am f Med Genet 1992;42:22-8.

13 Taalman RDFM, Weemaes CMR, Hustinx TWJ, Scheres JMJC, Clement JME, Stoelinga GBA. Chromosome studies in IgA-deficient patients. Clin Genet 1987;32:81-7.

14 Burgo GR, Duse M, Monafo V, Ascione A, Nespoli L. Selective IgA deficiency: clinical and immunological evaluation of 50 pediatric patients. Eur f Pediatr 1980;133:1016.

15 Finley SC, Finley WH, Noto TA, Uchida IA, Roddam RF. gA absence associated with a ring-18 chromosome. Lancet 1968;i:1095-6.

16 Roland B, Cox DM, Hoar DI, Fowlow SB, Robertson AS. A familial interstitial deletion of the long arm of chromosome 21. Clin Genet 1990;37:423-8.

17 McKusick VA, Amberger JS. Genetic map of the human genome. In: Scriver CR, Beaudet AL, Sly WS, Valle D, ed. The metabolic and molecular bases of inherited disease. 7 th $\mathrm{Ed}$. The metabolic and molecular bases of inherited

18 Theodoropoulos DS, Cowan JM, Elias ER, Cole C. Physical findings in $21 \mathrm{q} 22$ deletion suggest critical region for $21 \mathrm{q}-$ phenotype in q22. Am f Med Genet 1995;59:161-3.

19 Hertz B, Brachdt CA, Petersen MB, et al. Application of molecular and cytogenetic techniques to the detection of a de novo unbalanced $\mathrm{t}(1 \mathrm{l}$ q;21q) in a patient previously diagnosed as having monosomy 21. Clin Genet 1993;44:8994.

20 McGinniss MJ, Rosenberg C, Stetten G, et al. Unbalanced translocation, $t(18: 21)$, detected by fluorescence in situ hybridization (FISH) in a child with $18 \mathrm{q}$ - syndrome and a ring chromosome 21. Am f Med Genet 1993;46:647-51. 